\title{
Trifolium pratense ethanolic extract alters the gut microbiota composition and regulates serum lipid profile in the ovariectomized rats
}

Yixian Quah', Na-Hye Park², Eon-Bee Lee ${ }^{1}$, Ki-Ja Lee ${ }^{1}$, Jireh Chan Yi-Le ${ }^{3,4}$, Md. Sekendar Ali1 1,5,6, Seung-Hee Jang ${ }^{7}$, Min-Jeong Kim, Seung-Jin Lee ${ }^{8^{*}}$ and Seung-Chun Park*

\begin{abstract}
Background: Trifolium pratense (red clover) ethanolic extract (TPEE) has been used as a popular over-the-counter remedy for the management of menopausal symptoms. Prolonged consumption of herbal extract has been shown to regulate the composition of gut microbiota. This study was designed to elucidate the influence of TPEE on the gut microbiota composition in the ovariectomized (OVX) rats.

Methods: OVX rats were treated with TPEE at 125, 250,500 mg/kg/day, or controls (pomegranate extract, $500 \mathrm{mg} /$ $\mathrm{kg} /$ day; estradiol, $25 \mu \mathrm{g} / \mathrm{kg} /$ day) for 12 weeks. Gut microbiota analysis was conducted by extracting the microbial DNA from fecal samples and microbiome taxonomic profiling was carried out by using next-generation sequencing. The levels of serum biomarkers were analyzed using enzyme-linked immunosorbent assay (ELISA) kit. The prediction of functional biomarker of microbiota was performed using PICRUSt to investigate the potential pathways associated with gut health and serum lipid profile regulation. To study the correlation between gut microbiota composition and serum lipid levels, Spearman's correlation coefficients were defined and analyzed. Additionally, gas chromatographymass spectrometry analysis was conducted to uncover additional physiologically active ingredients.

Results: TPEE-treated OVX rats showed significant reduction in serum triglycerides (TG), total cholesterols (TCHOL), and LDL/VLDL levels but increase in HDL level. The alteration in the pathways involve in metabolism was the most common among the other KEGG categories. Particularly, TPEE also significantly reduced the relative abundance of sequences read associated with inflammatory bowel disease (IBD) and the peroxisome proliferator-activated receptor (PPAR) signalling pathway. TPEE intervention was seen to reduce the Firmicutes to Bacteroidetes (F/B) ratio in the OVX rats, denoting a reduction in microbial dysbiosis in the OVX rats. Correlation analysis at the phylum level revealed that Bacteriodetes and Proteobacteria were strongly correlated with serum TG, TCHOL and HDL levels. At the species level, Bifidobacterium pseudolongum group was seen to positively correlate with serum HDL level and negatively correlated with serum AST, ALT, LDL/NLDL, TCHOL, and TG levels.
\end{abstract}

Conclusions: TPEE treatment showed therapeutic benefits by improving the intestinal microbiota composition which strongly correlated with the serum lipid and cholesterol levels in the OVX rats.

\footnotetext{
*Correspondence: lee.seungjin@kitox.re.kr; parksch@knu.ac.kr

${ }^{1}$ College of Veterinary Medicine, Kyungpook National University, 80 Daehak-ro, Daegu 41566, Republic of Korea

${ }^{8}$ Reproductive and Development Toxicology Research Group, Korea

Institute of Toxicology, Daejeon, Republic of Korea

Full list of author information is available at the end of the article
}

(C) The Author(s) 2021. Open Access This article is licensed under a Creative Commons Attribution 4.0 International License, which permits use, sharing, adaptation, distribution and reproduction in any medium or format, as long as you give appropriate credit to the original author(s) and the source, provide a link to the Creative Commons licence, and indicate if changes were made. The images or other third party material in this article are included in the article's Creative Commons licence, unless indicated otherwise in a credit line to the material. If material is not included in the article's Creative Commons licence and your intended use is not permitted by statutory regulation or exceeds the permitted use, you will need to obtain permission directly from the copyright holder. To view a copy of this licence, visit http://creativecommons.org/licenses/by/4.0/. The Creative Commons Public Domain Dedication waiver (http://creativeco mmons.org/publicdomain/zero/1.0/) applies to the data made available in this article, unless otherwise stated in a credit line to the data. 
Keywords: Dysbiosis, Gut microbiota, Hypocholesterolemic effect, Menopause, Trifolium pratense

\section{Background}

As the average life span of women increases globally, women would be spending longer extent of their lives in the postmenopausal stage. Therefore, research into major physiological changes associated with menopause is receiving increased clinical and commercial interest [1]. Menopause is diagnosed when menstrual cycles permanently cease due to the exhaustion of ovarian oocytes resulting from aging. The major consequences of menopause such as urogenital atrophy, osteoporosis, cancer, obesity, and cardiovascular diseases are related primarily to estrogen deficiency. Previous clinical findings indicate that the treatment of postmenopausal osteoporosis should also consider preventative measures for cardiovascular disease because osteoporotic postmenopausal women are at higher risk of suffering cardiovascular events [2]. This is because estrogens exert a protective role in the cardiovascular system and are produced primarily in the ovaries via a process that utilize low-density lipoprotein cholesterol (LDL) as a substrate. When a woman is experiencing menopause, there is a depletion of follicles production which leads to the reduction of estrogen level. The negative feedback mechanism of estrogen induces the secretion of follicle stimulating hormones (FSH) and causes the desensitization of the follicles towards FSH [3]. The follicle is left without the ability to utilize the circulatory LDL for the synthesis of estrogen thus give rise to decreased estrogen production and increased in blood LDL levels [4]. Conventional hormone replacement therapy have raised serious concerns about its side effects and safety when it was used in prolonged treatments in relation to cardiovascular events and hormone-related cancers [5]. Consequently, researchers are attempting to identify alternative therapeutics including nutrients and botanicals which are rich in phytoestrogen to improve the abovementioned postmenopausal symptoms.

Trifolium pratense L. (Fabaceae) (red clover) extract has been consumed in many countries including India [6], Italy [7] and Turkey [8] as traditional medicines. The native Americans used this plant to treat topical skin problems and complications in lungs, nervous and reproductive system $[6,9,10]$. In Pakistan, $T$. pratense was used to treat fever, sore throat, and meningitis [11]. In Kosovo, the juice of its leaves was used as remedy for stomach disorders [12]. While in Estonia, T. pratense was taken as recreational medicine to treat heart diseases [13]. In recent years, T. pratense has become a popular over-the-counter remedy for the management of menopausal symptoms. This dietary supplement has shown potential in the treatment of several conditions associated with menopause $[14,15]$. Previous studies have also reported the effects of red clover extract and its active ingredients on vasomotor symptoms [14]. In addition, the benign effects of red clover extract have been reported in the breasts, endometrium, and neural structures [16]. Among the above multifunctional physiological activities, a meta-analysis on $T$. pratense reported that the plant have shown beneficial effects on the lipid profile of peri- and post-menopausal women [5].

A recent study demonstrated that women who have stopped menstruating have shown transformation in their compositional and functional features in their gut microbiota [17]. Although the mechanism of which is still unclear, estrogen has direct impact on the immune cells and variants in genes related to innate immunity and energy metabolism and thus this could cause the a shift in the gut microbiome [17]. Besides, the intestinal microbiome has been reported to play important role in isoflavone uptake, metabolism, and ultimately therapeutic efficacy [18]. Gut microflora metabolizes phytoestrogen daidzein, found in T. pratense extract [19], into equol which has high affinity for estrogen receptor (ER) $\beta$ [20]. Thus, the interaction between plant derived phytoestrogens with gut microbiota could yield positive estrogenic effects mainly in tissues expressing ER $\beta$ which mediates cholesterol metabolism [21, 22]. Prolonged consumption of herbal extract has been shown to regulate the composition of gut microbiota [23]. With an increasing understanding of human gut microbiota, it has become apparent that the microbiology of the gut is closely related to health and disease [23].

In short, the literatures pertaining to the effect of $T$. pratense in regulating the lipid profile and the effect of menopause in alteration of gut microbiota composition which regulates serum lipid profile strongly suggest that $T$. pratense could regulate intestinal microbiota and serum lipid profile in menopausal women. TPEE-treated OVX rats could provide insights about the interrelationship between serum lipid profile and the changes of intestinal microflora.

\section{Methods}

Preparation of ethanolic extract from Trifolium pratense and species identification

Dried $T$. pratense was taxonomically identified by Dowgene DNA Testing Company (Seoul, Republic of Korea) using mitochondrial DNA sequencing. The DNA 
sequencing data from our study was 100\% identical to previously reported sequences of $T$. pratense in the NCBI GenBank database with the accession numbers: KY860927.1, KX555647.1, KU956946.1, FJ554421.1, DQ312029.1, and DQ307475.1 (Additional File 1). The raw sequence data was deposited to Sequence Read Archive (SRA) with accession number: SRR14492033, project number: PRJNA727441.

We obtained the species identified T. pratense from a certified company, Teazen Co. Ltd. (Anyang-si, Republic of Korea), which was cultured and originated from Albania (Certificate of Origin Number A19690728 was issued on 2019-02-11 by Industrie- und Handelskammer Würzburg-Schweinfurt, verification code: GSY4$3 \mathrm{M} 2 \mathrm{C}-\mathrm{CP} 9 \mathrm{C})$, with the voucher number P-338852. The relevant institutional permissions to collect $T$. pratense was obtained. This study complies with the with local and national regulations. The extraction was done by DaeHo Co. Ltd. (Gyeonggi-do, Republic of Korea), abiding to GMP standards and the Food Item Manufacturing Report. Briefly, macerated T. pratense leaves and flowers $(30 \mathrm{~kg})$ were added to extraction solvent (30\% ethanol) at 1:30 ratio. The sample was extracted twice for $3 \mathrm{~h}$ at $85^{\circ} \mathrm{C}$; the extract obtained from each extraction step was filtered by $1-\mu \mathrm{m}$ filtration. The resulting $T$. pratense ethanolic extract (TPEE) was then incorporated with dextrin at a 7:3 ratio (extract:dextrin) during a spray-drying step at $180^{\circ} \mathrm{C}$ for animal experiment as the prototype of a product (Additional file 2). The extract was standardized and managed by two functional indicator components: formononetin and biochanin A (Additional file 2). HPLC quantification of the indicative compounds (formononetin and biochanin A) in TPEE was conducted and reported in our previous study [24].

\section{GC-MS analysis}

In addition to the known functional ingredients of $T$. pratense, GC-MS analysis on the components in this plant was conducted to uncover additional physiologically active ingredients. TPEE was dissolved in 70\% ethanol at $1 \mathrm{mg} / \mathrm{mL}$. GC analysis was performed on Agilent 7890A GC and 5975C MSD equipped with injector $\left(250^{\circ} \mathrm{C}\right)$ and a flame ionization detector (FID). Helium gas was used as carrier gas $(1 \mathrm{~mL} / \mathrm{min})$ and the capillary column used was DM- $5 \mathrm{~ms}(60 \mathrm{~m} \times 250 \mu \mathrm{m}$, film thickness $0.25 \mu \mathrm{m})$. The column temperature was kept at $60^{\circ} \mathrm{C}$ for $1 \mathrm{~min}$ and then heated to $300^{\circ} \mathrm{C}$ with a $5^{\circ} \mathrm{C} / \mathrm{min}$ rate and kept constant at $300^{\circ} \mathrm{C}$ for $20 \mathrm{~min}$. GC-MS analysis was performed using a GC-MSD. The column temperature was kept at $60^{\circ} \mathrm{C}$ for $1 \mathrm{~min}$ and programmed to $300^{\circ} \mathrm{C}$ at a rate of $5^{\circ} \mathrm{C} / \mathrm{min}$ and kept constant at $300^{\circ} \mathrm{C}$ for $20 \mathrm{~min}$. The flow rate of helium as carrier gas was $1 \mathrm{~mL} /$ min. The mass range for GC-MS was 35-600 (m/z). MS were taken at $70 \mathrm{eV}$. HPLC quantification of the indicative compounds (formononetin and biochanin A) in TPEE was conducted and reported in our previous study [24].

\section{Animal grouping and treatments}

Healthy 8-week-old female Sprague-Dawley rats (body weight: $190-230 \mathrm{~g}$ ) were housed in an air-conditioned environment $\left(22^{\circ} \mathrm{C} \pm 2{ }^{\circ} \mathrm{C}\right.$, humidity of $50-60 \%$ with a $12 \mathrm{~h} \mathrm{light/dark} \mathrm{cycle} \mathrm{with} \mathrm{lights} \mathrm{on} \mathrm{at} \mathrm{6:00} \mathrm{A.M).} \mathrm{The} \mathrm{ani-}$ mals were allowed free access to Teklad certified irradiated global 18\% protein rodent diet (2918C, Envigo, USA) supplied by Koatech (Gyeonggi-do, Republic of Korea) and distilled water. Animal handling complied with ARRIVE guidelines and was performed in compliance with the Guide for the Care and Use of Laboratory Animals provided by the US National Institutes of Health. This study was approved by the institutional animal care and use committee of the Kyungpook National University, Republic of Korea (approval number: KNU 2018121). A total of 70 rats were acclimatized for 1 week. In this study, $\mathrm{n}$ refers to number of animals. The rats were randomly allocated as either Sham-operated $(n=10)$ or bilaterally ovariectomized (OVX; $n=60)$. Oral administration of sample, positive controls or vehicle to the rats began 1 week after surgery. The experimental timeline was shown in Additional file 3.

The OVX rats were randomly divided into six groups and each group was composed of 10 rats. The group were named after the treatment they received: Negative control $(\mathrm{NC})=\mathrm{OVX}+30 \%$ dextrin; Pomegranate extract $(\mathrm{PomE})=\mathrm{OVX}+500 \mathrm{mg} / \mathrm{kg} /$ day pomegranate extract; Estradiol $(\mathrm{E})=\mathrm{OVX}+25 \mu \mathrm{g} /$ $\mathrm{kg} /$ day $\quad$ estradiol; $\quad \mathrm{T} 125=\mathrm{OVX}+125 \mathrm{mg} / \mathrm{kg} /$ day TPEE; $\quad \mathrm{T} 250=\mathrm{OVX}+250 \mathrm{mg} / \mathrm{kg} /$ day $\quad \mathrm{TPEE}$; $\mathrm{T} 500=\mathrm{OVX}+500 \mathrm{mg} / \mathrm{kg} /$ day TPEE .

Sham and NC groups were administered the same volume of $30 \%$ dextrin by oral gavage. Three controls were as follows: Sham group (representing the presence of endogenous estradiol in the body), E group (administration of estradiol, a positive control drug used for hormone replacement therapy in the treatment of postmenopausal osteoporosis [25]) and PomE group (pomegranate extract as a plant extract positive control for osteoporosis [26, 27] and cardiovascular disease (ClinicalTrials.gov Identifier: NCT01102140) intervention). PomE was purchased from Hanil PFC Co., Ltd. (Seoul, Republic of Korea), which was approved and recognized by MFDS (Ministry of Food and Drug Safety) as health functional food. Chemical characterization of the PomE has been carried out with LC/MS/MS and was reported in previous report [28].

At the end of the treatment, the rats were anesthetized with $\mathrm{CO}_{2}$ inhalation until unconscious and blood 
samples were taken via cardiac exsanguination. The blood samples were centrifuged for $10 \mathrm{~min}$ at $1000 \mathrm{x} g$ to obtain serum and then stored at $-80^{\circ} \mathrm{C}$ until use. The fecal samples were collected and stored at $-80^{\circ} \mathrm{C}$ until DNA extraction for microbiota profiling.

\section{Preparation of specimens}

The harvested liver samples were immediately fixed in $10 \%$ buffered formalin solution. Paraffin embedded blocks $(5 \mu \mathrm{m})$ were stained with hematoxylin and eosin (H\&E) for histology analysis under an optical microscope.

\section{Serum biomarker analysis}

Serum for biomarker analysis were maintained at $-80^{\circ} \mathrm{C}$ until the respective tests were conducted. Levels of serum biomarkers were measured using an enzymelinked immunosorbent assay (ELISA) kit (Cusabio Biotech, Wuhan, China). Sample analysis and calibration curves were plotted according to the manufacturer's instructions.

\section{Min-max normalization}

To allow direct comparison among the data obtained from different analysis in our study, a metric system was constructed. The data obtained in each analysis were normalized using Min-Max normalization [24] to ensure the output was bounded between 1 and 5. Specifically, the $\mathrm{NC}$ was scored as 1 and the Sham as 5. The general formula of the Min-Max normalization is as follows:

$$
x^{\prime}=\left(\frac{x-\min (X)}{\max (X)-\min (X)}\right) \text {, where } \mathrm{x} \in \mathrm{X}, \mathrm{X} \text { are real }
$$
numbers

\section{Gut microbiota analysis}

Group NC, Sham, E and T250 were selected for the elucidation for their gut microbiota composition. Group T250 was selected to be the representative for the TPEE treatment groups due to the lack of significance differences among the three treatment dosages in the serum biomarker levels. Microbial DNA from fecal samples was extracted using a QIAamp DNA Stool Mini Kit (Qiagen Inc., Hilden, Germany) according to the manufacturer's instructions. Quality control requirement of the DNA sample was met by achieving DNA concentration of $\geq 15 \mathrm{ng} / \mu \mathrm{L}$ and $A_{260} / A_{280}$ ratio of $\geq 1.8$. Microbiome profiling was conducted based on 16S rRNA gene sequences obtained from the rats' fecal sample, it was amplified by universal bacterial PCR primers 27F (AGR GTTTGATYMTGGCTCAG) and 1492R (GGYTACCTT GTTACGACTT) by the Pacific Biosciences (PacBio) RS1 conducted in ChunLab Inc. (Seoul, Republic of Korea). Microbiome Taxonomic Profile (MTP) was generated from next generation sequencing (NGS) using the
EzBioCloud MTP pipeline and EzBioCloud 16S database PKSSU4.0 [29]. Sequences were separated by unique inhouse codes, and low- quality reads (sequences with the read lengths of $<100$ or $>2000 \mathrm{bp}$; average $\mathrm{Q}$ values $<25$, and sequences that do not match with any of the reference sequences with $\leq 97 \%$ similarity cutoff were clustered using UCLUST with $97 \%$ similarity cutoff) were filtered out. The number of reads (total reads pre-filter, total valid reads, filtered reads) and the read lengths for each sample were presented in Additional file 4. The species identified, query sequences achieved $97 \%$ similarity with the EzBioCloud 16S database and the OTUs obtained by those which did not achieve $97 \%$ similarity with the database (which then clustered using UCLUST tool) were used to generate a final set of OTUs for alpha diversity indices (including Shannon and Chaol indices). Secondary analyses including beta diversity and functional biomarker discovery were analyzed using EzBioCloud 16S-based MTP app [29]. The prediction of functional biomarker of microbiota was performed using the PICRUSt (ver. 1.0.0) [30].

\section{Statistical analysis}

Data are expressed as means \pm standard error of the mean $(\mathrm{SEM})$, and statistical significance $(p<0.05)$ was determined by one-way ANOVA with Tukey's post-hoc analysis using GraphPad Prism 5.01 (La Jolla, CA, USA). The significantly different KEGG pathway was selected by corrected $p$ value $<0.05$ using Kruskal-Wallis $\mathrm{H}$-test with Benjamin-Hochberg correction.

\section{Results}

GC-MS analysis of Trifolium pratense ethanolic extract

GC-MS analysis of TPEE led to the identification of 18 functional phytocomponents (Table 1). Particularly, the main constituents of TPEE identified by GC-MS analysis were mome inositol (68.21\%), 9,12,15-octadecatrienoic acid, (Z,Z,Z)- (3.20\%), hexadecanoic acid (1.92\%), silane, diethoxydimethyl- (1.32\%), ethane, 1,1-diethoxy- (1.14\%), and 1-Butanol, 3-methyl-, acetate (1.03\%) (Fig. 1). Remarkably, mome inositol $\left(\mathrm{C}_{7} \mathrm{H}_{14} \mathrm{O}_{6}\right)$ was the most abundant in this extract.

\section{Effects of Trifolium pratense ethanolic extract on serum biomarker levels}

Serum biomarker analysis revealed that TPEE treatment significantly reduced serum triglyceride (TG) and lowdensity lipoprotein/very low-density lipoprotein (LDL/ VLDL) levels in OVX rats while significantly increased serum high-density lipoprotein (HDL) levels in OVX rats in a dose-dependent manner (Fig. 2). Administration of TPEE to OVX rats did not significantly affect AST, ALT, ALP and TBIL levels compared to NC and Sham groups 
Table 1 Phytocomponents identified in Trifolium pratense ethanolic extract by GC-MS

\begin{tabular}{llll}
\hline Peak & RT & Compound & Area \% \\
\hline 1 & 6.581 & Ethane, 1,1-diethoxy- & 1.135 \\
2 & 6.854 & Silane, diethoxydimethyl- & 1.321 \\
3 & 13.143 & Methoxyacetic acid, 2-tridecyl ester & 0.281 \\
4 & 14.785 & Methoxyacetic acid, 2-tetradecyl ester & 0.257 \\
5 & 16.020 & 1-Butanol, 3-methyl-, acetate & 1.026 \\
6 & 16.134 & Silane, trichlotodocosyl- & 0.612 \\
7 & 17.606 & 4-Amino-1,2-thiazole-3-carboxylic acid & 0.252 \\
8 & 18.874 & Nonyl heptafluorobutyrate & 0.183 \\
9 & 19.112 & Dodecane & 0.308 \\
10 & 19.189 & Methyl salicylate & 0.333 \\
11 & 20.663 & 2-Methyl-4-(4-methoxiphenyl)-2-pentene & 0.463 \\
12 & 21.251 & Methoxyacetic acid, 2-tetradecyl ester & 0.233 \\
13 & 23.572 & Eugenol & 0.215 \\
14 & 24.457 & 9-Tricosene, (Z)- & 0.221 \\
15 & 24.660 & Tetradecane,2,6,10-trimethyl- & 0.227 \\
16 & 31.462 & Mome inositol & 68.206 \\
17 & 37.261 & Hexadecanoic acid & 1.924 \\
18 & 40.681 & 9,12,15-Octadecatrienoic acid, (Z,Z,Z)- & 3.198 \\
\hline
\end{tabular}

$(p>0.05)$. However, there were significant reductions $(p<0.05)$ in the levels of TP and ALB (Table 2). The histology analysis on liver did not show significant changes in the treatment groups compared to the control groups (Additional File 5). From the scoring of the serum lipid markers and liver function indicators shown in Fig. 2E, TPEE showed promising positive effects on regulating serum cholesterol levels compared to PomE treatment (a marketed plant-based positive control). However, its effects on the liver function indicators were slightly weaker compared to that of $\mathrm{E}$ and PomE treatments.

\section{Influence of Trifolium pratense ethanolic extract} on the composition of gut microbiota of OVX rats Effects of Trifolium pratense ethanolic extract on the diversity of the gut microbiota

The alpha diversity of the gut microbiota in the rats were assessed by Shannon and Chaol diversity indices (Fig. 3A). The Shannon diversity index indicated that there was no significant difference among all the groups $(p>0.05)$. Interestingly, significant alteration in the Chao1 index was observed in the Sham group compared to the OVX groups $(p<0.001)$. Rarefaction curve was presented to illustrate the number of OTUs has reached a horizontal asymptote. This implies that the sequencing depth is sufficient for analysis (Additional file 6).

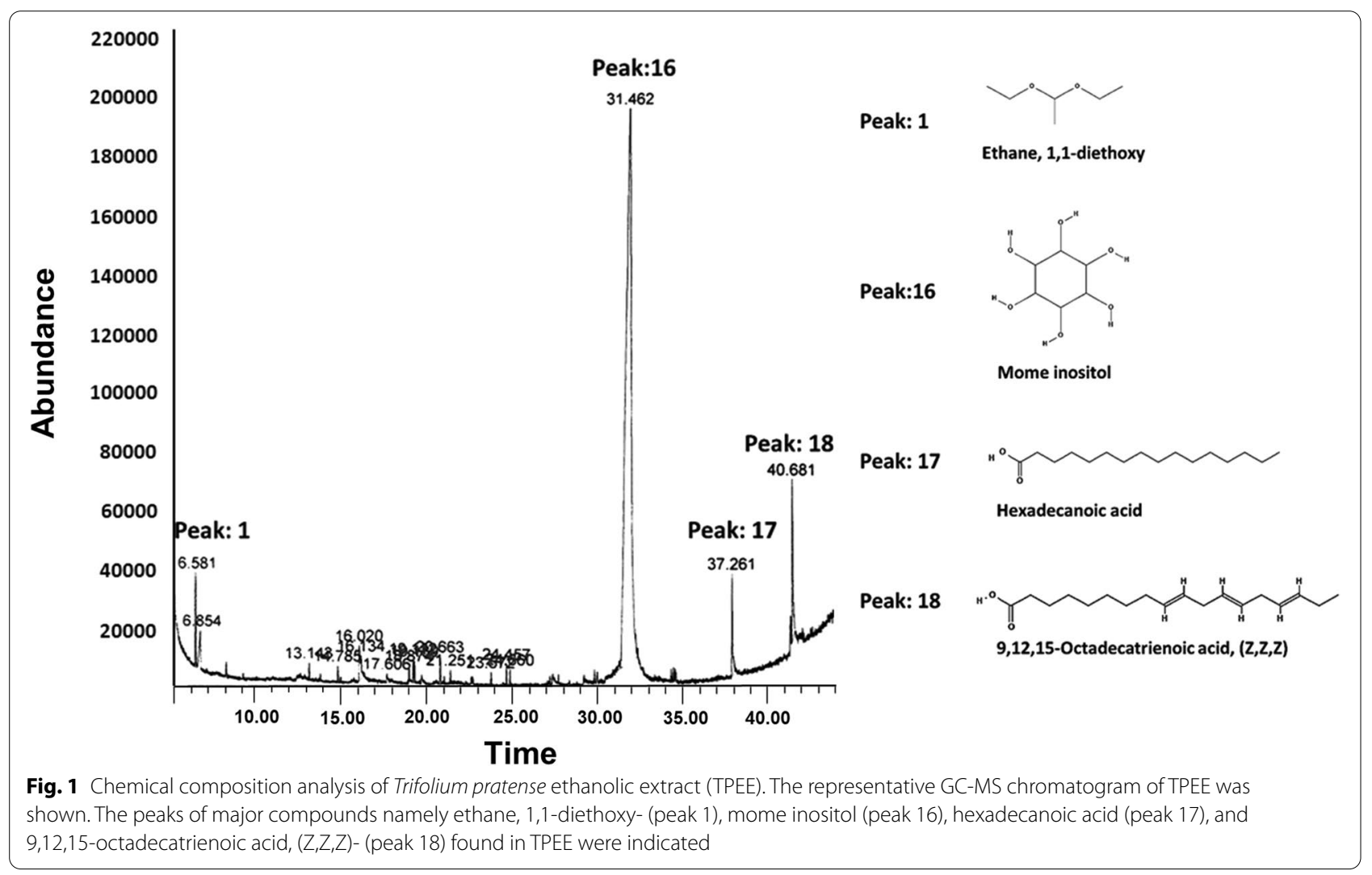



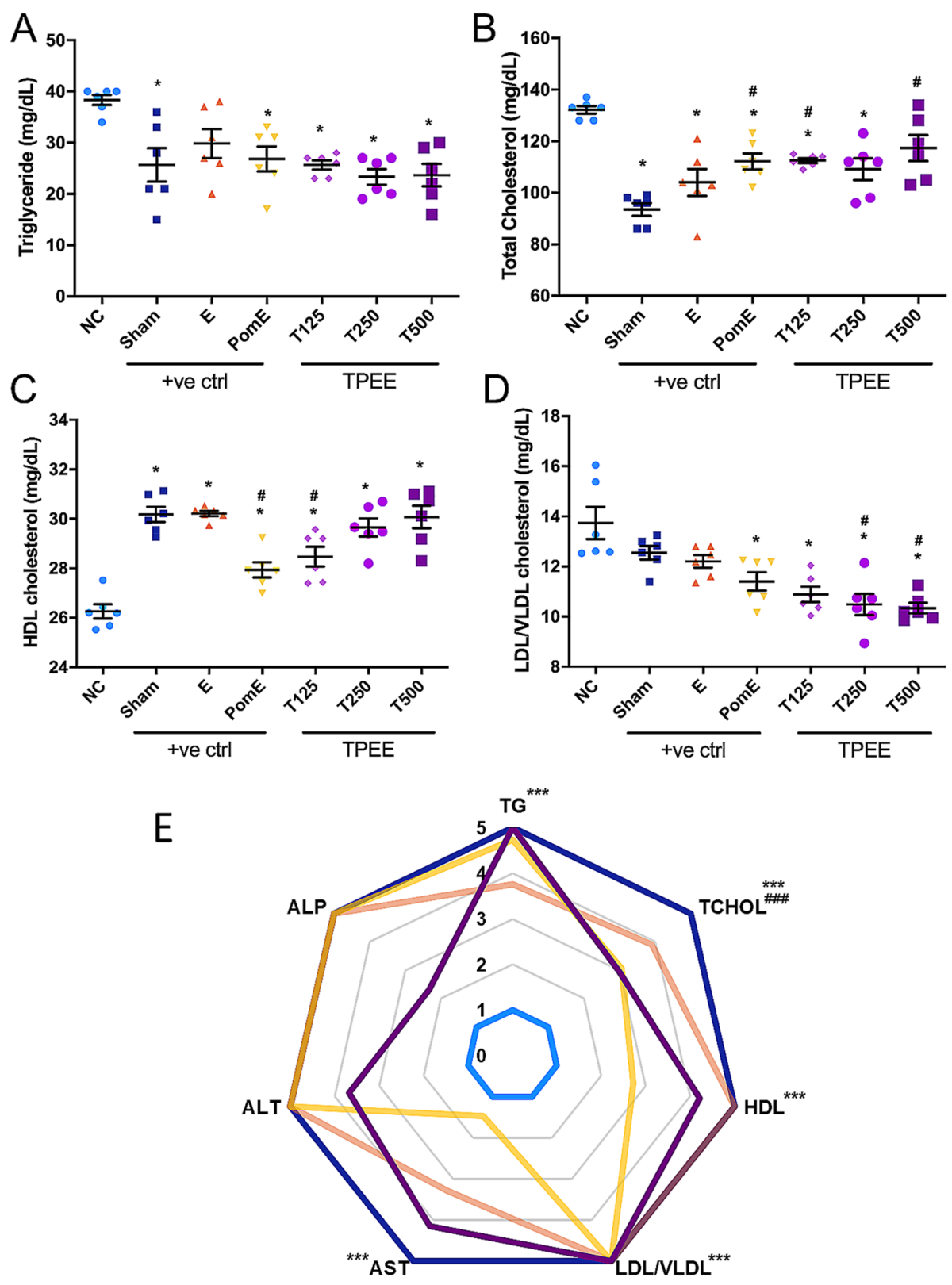

एNC

Sham

E

PomE

TPEE

Fig. 2 The effects of Trifolium pratense ethanolic extracts on the serum lipid profiles. Serum triglyceride (A), total cholesterol (B), HDL cholesterol $(\mathbf{C})$ and LDLNLDL cholesterol (D) levels in ovariectomized (OVX) rats were shown. Data are presented as means $\pm \mathrm{SEM}, n=6$. ${ }^{*} p<0.05$ compared with the negative control (NC) group, $" p<0.05$ compared with the positive control (Sham) group determined by one-way ANOVA with Tukey's post-hoc analysis. Summary of serum lipid markers and liver enzymes with the negative control (NC) scored as 1 and Sham scored as 5 (E). Data are presented as means \pm SEM,$n=6 .{ }^{* *} p<0.001$ TPEE compared with the negative control (NC) group, ${ }^{\# \#} p<0.001$ TPEE compared with the positive control (Sham) group determined by one-way ANOVA with Tukey's post-hoc analysis

\section{Beta diversity distance analysis}

Weighted Fast UniFrac analysis was performed (Fig. 3B) and the data of the UniFrac matrices were projected on to a 3-dimensional plot using principal coordinates analysis (PCoA). Weighted PCoA analysis showed that most of the OVX samples (E, NC and TPEE) were largely indistinguishable and clustered closely to each other regardless of treatments. Sham group, on the other hand, has shown distinct clustering from the OVX samples. Visible 
Table 2 Effect of Trifolium pratense ethanolic extract on the levels of serum biomarkers

\begin{tabular}{lllllll}
\hline Group & AST (U/L) & ALT $(\mathbf{U} / \mathbf{L})$ & ALP $(\mathbf{U} / \mathbf{L})$ & TP $(\mathbf{g} / \mathbf{d L})$ & ALB (g/dL) & TBIL (mg/dL) \\
\hline NC & $269.00 \pm 65.00$ & $72.00 \pm 2.90$ & $247.00 \pm 11.00$ & $6.47 \pm 0.09$ & $4.00 \pm 0.04$ & $0.07 \pm 0.02$ \\
Sham & $207.00 \pm 16.00$ & $72.00 \pm 1.90$ & $246.00 \pm 18.00$ & $6.15 \pm 0.12^{*}$ & $3.90 \pm 0.06$ & $0.03 \pm 0.02$ \\
E & $234.00 \pm 25.00$ & $90.00 \pm 9.00$ & $223.00 \pm 29.55$ & $5.88 \pm 0.05^{*}$ & $3.60 \pm 0.03^{* \#}$ & $0.02 \pm 0.02$ \\
PomE & $262.00 \pm 18.00$ & $99.00 \pm 2.20^{* \#}$ & $227.00 \pm 15.15$ & $5.65 \pm 0.08^{* \#}$ & $3.70 \pm 0.05^{* \#}$ & $0.02 \pm 0.02$ \\
T125 & $228.00 \pm 9.30$ & $80.00 \pm 4.80$ & $235.30 \pm 16.43$ & $5.73 \pm 0.02^{* \#}$ & $3.60 \pm 0.02^{* \#}$ & $0.05 \pm 0.02$ \\
T250 & $226.00 \pm 22.00$ & $87.00 \pm 5.40$ & $278.70 \pm 6.766$ & $5.67 \pm 0.07^{* \#}$ & $3.60 \pm 0.03^{* \#}$ & $0.05 \pm 0.02$ \\
T500 & $143.00 \pm 18.00^{*}$ & $66.00 \pm 4.00$ & $290.50 \pm 17.16$ & $5.88 \pm 0.04^{*}$ & $3.60 \pm 0.03^{* \#}$ & $0.03 \pm 0.02$ \\
\hline
\end{tabular}

Values are presented as mean \pm Standard error, $n=6$

AST aspartate transaminase, $A L T$ alanine transaminase, $A L P$ alkaline phosphatase, $T P$ total protein, $A L B$ albumin, $T B I L$ total bilirubin * $p \leq 0.05$ compared with the NC group

\# $p \leq 0.05$ compared with the Sham group
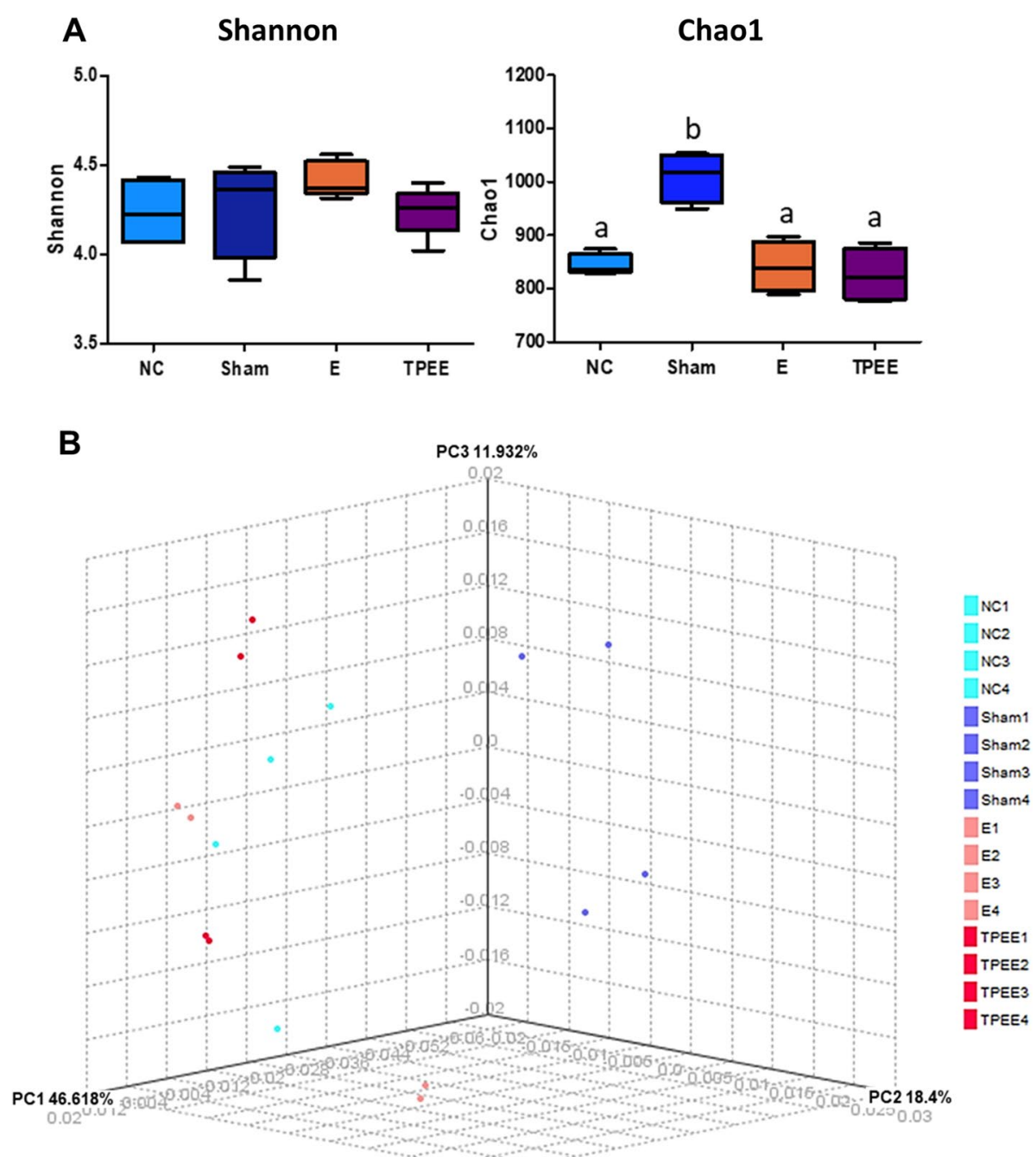

Fig. 3 The alpha and beta diversity analyses of each treated group. Shannon and Chao1 index (A); beta diversity indicated by PCoA plot of weighted UniFrac distance showing sample clustering by treatment groups (B). Data are presented as means \pm SEM, $n=4$. Means denoted by a different letter indicate significant differences between treatments $(p<0.05)$ determined by one-way ANOVA with Tukey's post-hoc analysis 
OVX-to-Sham variation was observed which was largely distributed at principal coordinate 1 (PC1) of $46.618 \%$.

Bray-Curtis distance analysis was performed to provide further information on similarities and differences of gut microbiota composition between and within groups. The diversity distance was performed to compare TPEE with the $\mathrm{NC}$ and Sham groups. Figure 4A-C illustrate that the median of inter-group distance between NC, Sham and TPEE were generally larger than intra-group distance. Figure 4D illustrates the summary of the median distance among the three groups (NC, TPEE and Sham groups). The Bray-Curtis diversity distance analysis showed that the gut microbiota diversity in OVX rats drifted under the TPEE treatment with the median distance of 0.303 from the NC group. The median distance between Sham and TPEE (0.624) was seen to be slightly closer than distance between Sham and NC (0.682). Permutational multivariate analysis of variance (PERMANOVA) analysis showed that the inter-group distances were significantly different at $5 \%$ confidence interval $(p=0.036)$.

\section{Predicted functions of gut microbiome}

The function of gut microbiota was predicted by KEGG pathways using PICRUSt [31]. The significantly different pathway was selected by corrected $p$ value $<0.05$ using Kruskal-Wallis H-test with Benjamin-Hochberg correction. In Fig. 5, the proportion of sequence reads associated with metabolism pathway was the highest among the pathway classes. When comparing TPEE with Sham and NC groups, the proportion of sequences related to environmental information processing was the second highest, followed by organismal systems. Two metabolic pathways related to gut health and serum lipid profiles were selected for further investigation (Fig. 5D). The median relative abundance of the gut microbiome in the
TPEE group associated with inflammatory bowel disease (IBD) was 0.013 while NC group was $0.016(p=0.0209)$. The significant orthologs that are in this pathway were transcription factor p65 (RELA), transcription factor Maf (c-maf), and toll-like receptor 4 (TLR4) with the KEGG orthology (KO) of K04735, K09035, and K10160, respectively. The median relative abundance of the gut microbiome in the TPEE group associated with peroxisome proliferator-activated receptor (PPAR) signalling pathway was 0.114 while $\mathrm{NC}$ group was $0.124(p=0.0433)$. The significant orthologs that are in the PPAR signalling pathway were acyl-coA oxidase (K00232), stearoyl-coA desaturase (SCD-1) (K00507), glycerol kinase (GyK) (K00864), integrin-linked kinase (ILK) (K06272), retinoid-X receptor beta (RXR) (K08525), and apolipoprotein A-I (APOA1) (K08757).

\section{Correlations of serum biomarkers and gut microbiota}

Spearman's correlation coefficients between the composition of gut microbiota and lipid biomarkers in OVX rats at the phylum (Fig. 6A) and species (Fig. 6B) levels were defined and hierarchical clustering was applied using Ward's linkage. The heatmap illustrated that Bacteriodetes correlated negatively with serum TG and TCHOL level while correlated positively with serum HDL level (Fig. 6A). Conversely, Proteobacteria correlated positively with serum TG, TCHOL and LDL/VLDL level while negatively with serum HDL level. Bifidobacterium pseudolongum group was seen to positively correlated with serum HDL level and negatively correlated with serum AST, ALT, LDL/VLDL, TCHOL, and TG levels (Fig. 6B).

\section{TPEE-altered intestinal microbiota composition in OVX rats}

From our taxonomic analysis, the gut microbiota of rats consisted of Firmicutes, Proteobacteria,
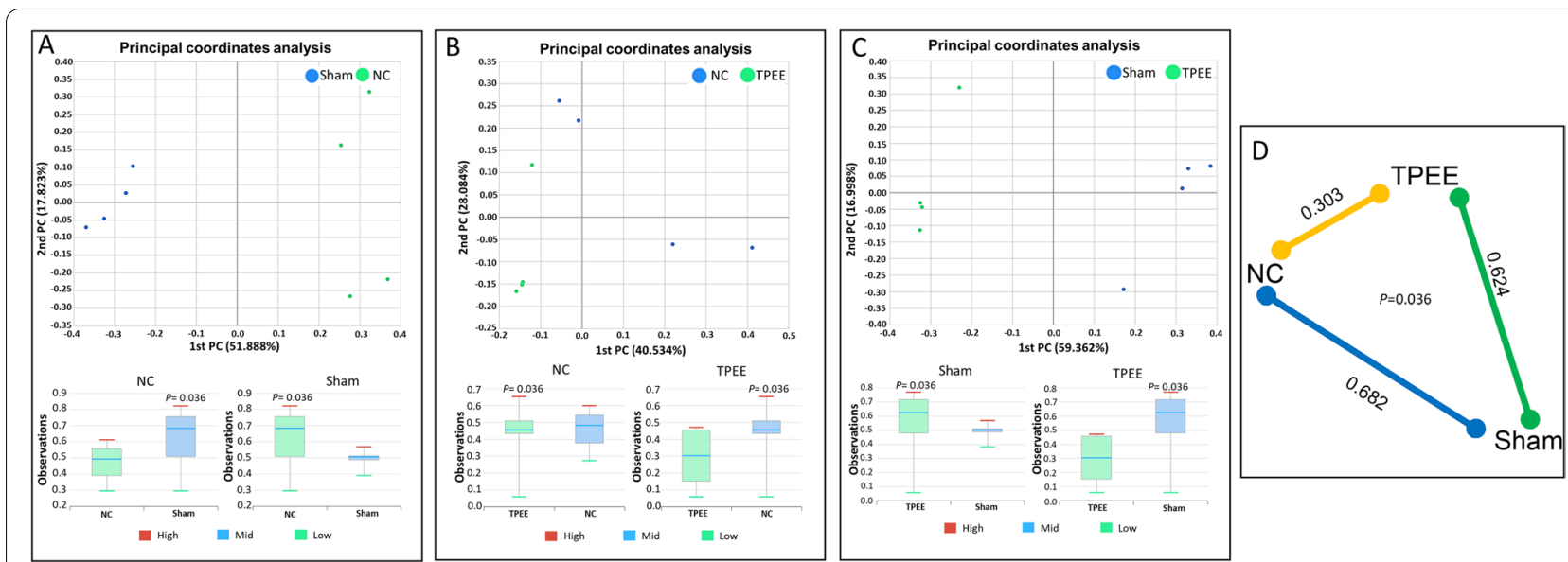

Fig. 4 Bray-Curtis diversity distance analysis. The gut microbiota among the groups were compared using the PCoA plot (A-C). The summary of distances between NC, TPEE and Sham groups were shown (D) 


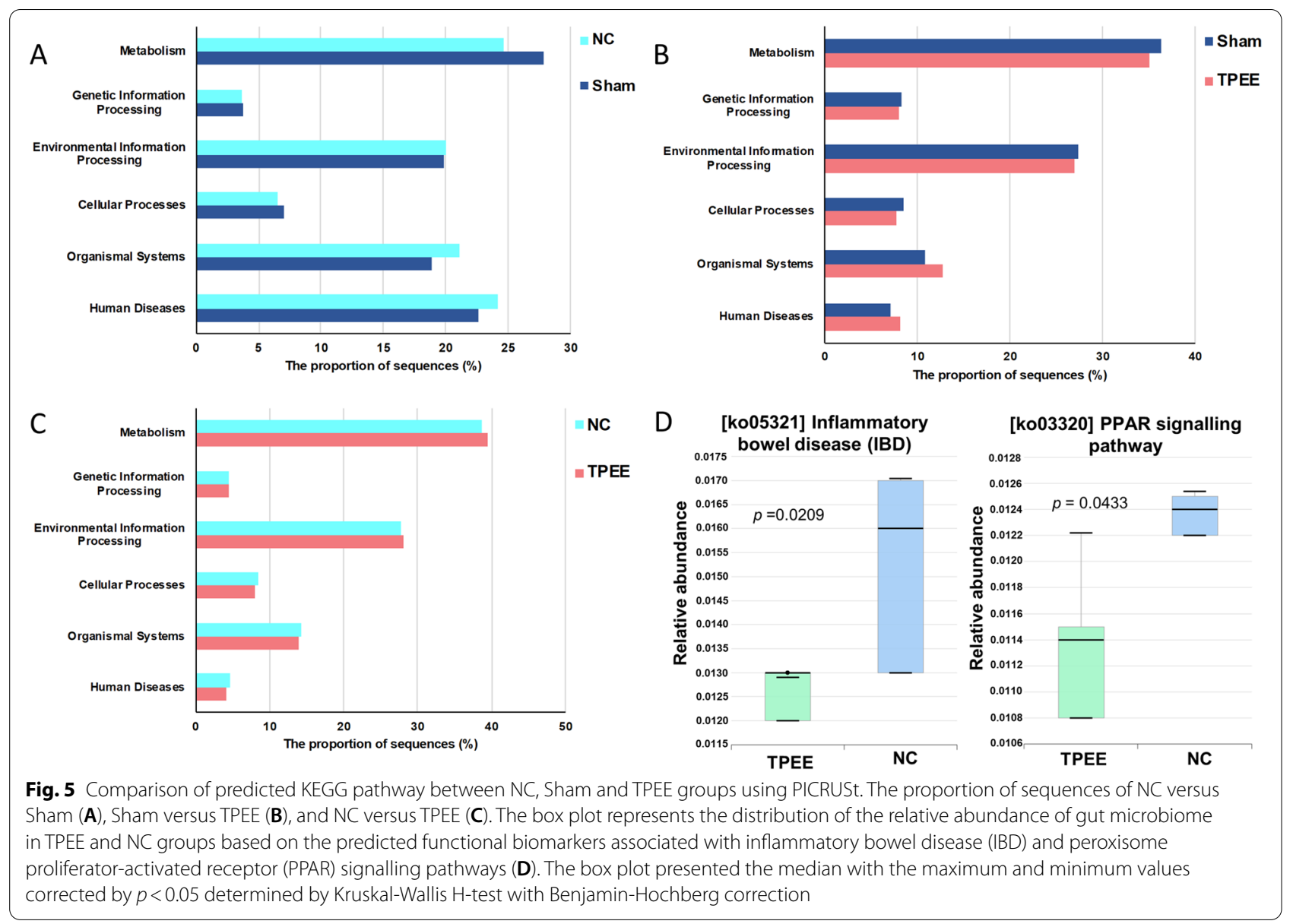

Verrucomicrobia, Actinobacteria, and Bacteroidetes at the phylum level. Firmicutes was the most abundant phylum (found in all the animals), followed by Verrucomicrobia and Bacteroidetes (Fig. 7A and B). TPEE intervention significantly improved intestinal microbiota composition in OVX rats by recovering an abundance of Verrucomicrobia $(18.63 \%)(p<0.05)$ and reducing Firmicutes abundance $(77.23 \%)(p<0.05)$ compared to the NC group (5.94 and $88.89 \%$, respectively). Bacteroidetes were noticeably more abundant in the Sham group $(22.6 \%)$ than in NC $(1.09 \%, p<0.05)$, $\mathrm{E}$ and TPEE (5.83, $1.22 \%$, respectively) $(p>0.05)$. The Firmicutes/Bacteroidetes (F/B) ratio was found to be largely reduced in Sham group compared to NC group $(p<0.01)$ as shown in Fig. $7 \mathrm{C}$. Treatment with $\mathrm{E}$ and TPEE in OVX rats significantly reduced the F/B ratio compared to that of NC group. No significant difference was observed between E, TPEE and Sham group in terms of $\mathrm{F} / \mathrm{B}$ ratio. The strain with the highest relative abundance in the taxonomic composition analysis was Akkermansia muciniphila. Its abundance was highest in the TPEE group relative to the $\mathrm{E}$ and $\mathrm{NC}$ groups
(Fig. 7D). In the present study, the relative abundance of Lactococcus garvieae was significantly higher in TPEEtreated groups than that in the NC group (Fig. 7E).

\section{Discussion}

Red clover extract has been consumed as a dietary supplement for handling menopausal symptoms, cholesterol levels and osteoporosis [14, 15, 32]. Long term consumption of herbal extracts can shape the distribution and composition of the gut microbiota [23]. Therefore, it is important to study the interaction between gut microbiota and the administration of TPEE. In this study, TPEE and exogenous estrogen treatment did not significantly affect the gut microbiota species evenness and richness in OVX rats. This suggests that exogenous estrogen and TPEE treatments, known to contain phytoestrogens, could not reverse the decline in microbial diversity caused by overiectomization. However, TPEE administration have positively affected the population of beneficial bacteria strains that may contribute to the regulation of serum lipid levels. 


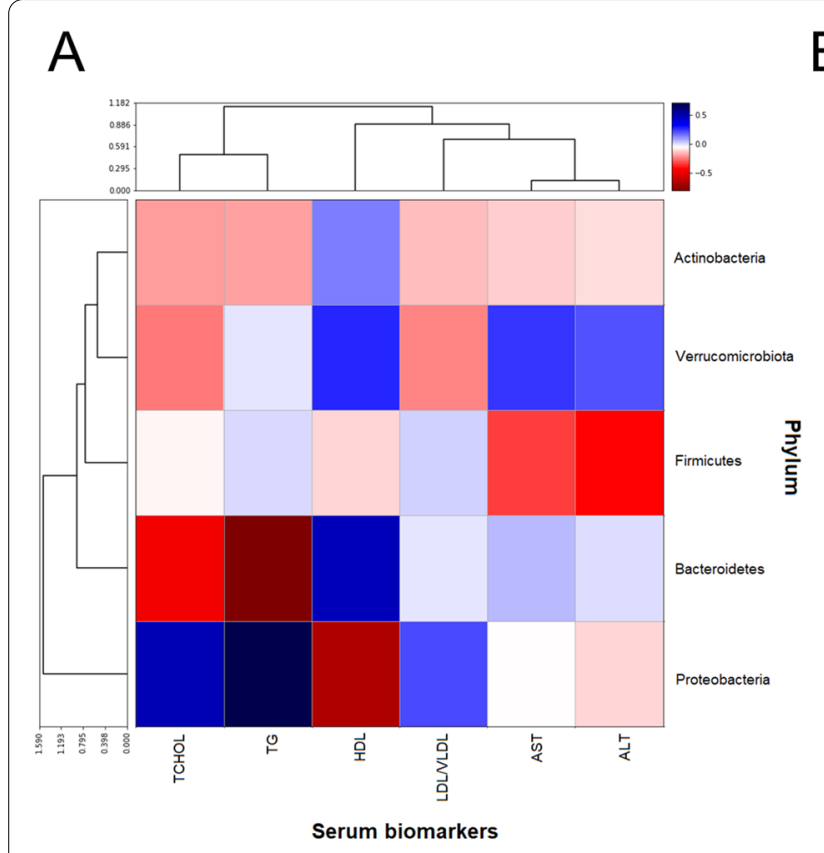

B

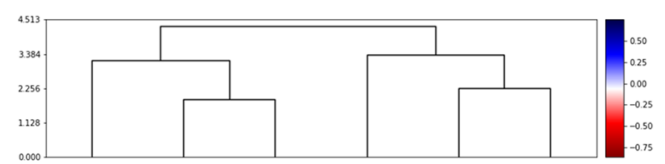

Serum biomarkers

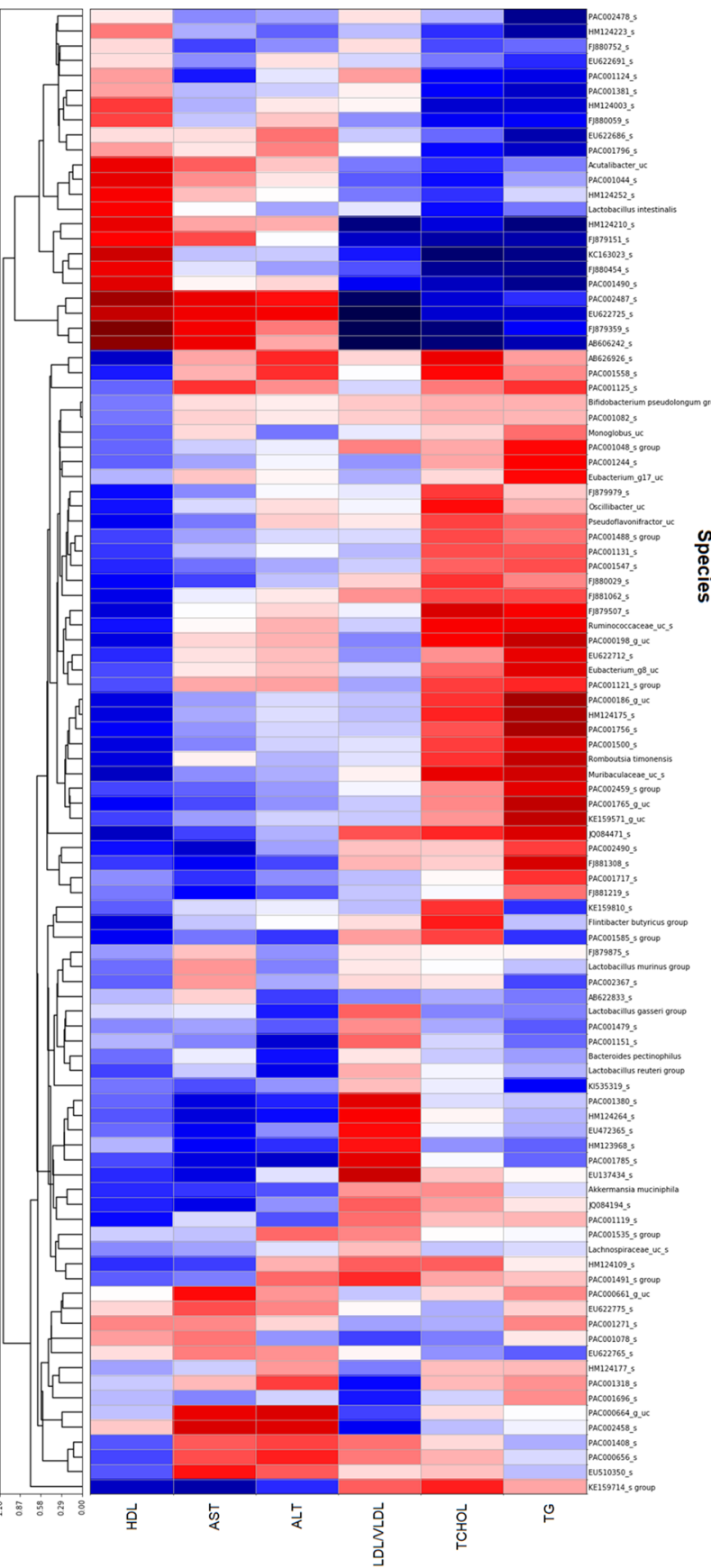

Serum biomarkers

Fig. 6 Heat map created and sorted based on hierarchical clustering of both bacteria and serum biomarkers. Dendrogram at the $y$-axis indicated the clustering of gut microbiota at the phylum level $(\mathbf{A})$ or species level (B) in relation to each of the serum biomarkers. Dendrogram at the $x$-axis indicated the association clustering of serum biomarkers in relation to each phylum or species 


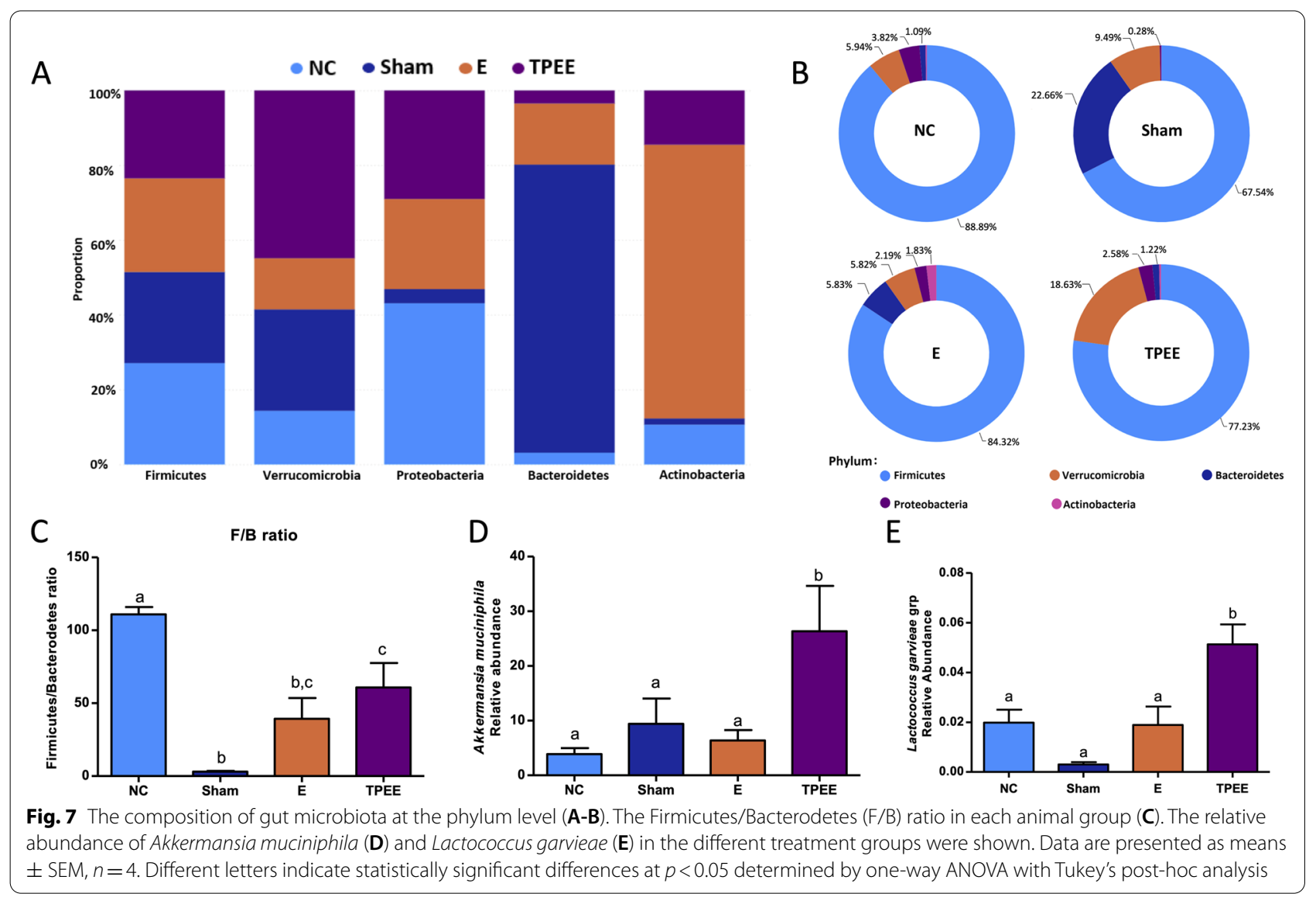

Prediction of functional biomarkers showed that pathways associated to metabolism, genetic information processing, organismal systems and human diseases were found to alter with the influence of TPEE in the OVX rats following the same pattern as Sham (Fig. 5A-C). Particularly, TPEE treatment was found to yield lower abundance of sequence reads associated with IBD compared to the NC group (Fig. 5D). IBD is characterized by chronic inflammation of the intestine due to environmental and genetic factors, infectious microbes, and the dysregulated immune system [33], which includes Crohn's disease and ulcerative colitis. The significant KOs found in this pathway, namely TLR4 and RELA, involve in the toll-like receptor signalling pathway which leads to inflammation [34]. Besides, RELA also plays a role in the cytokine-cytokine receptor interaction in Th1 lymphocyte to induce IFN- $\gamma$ expression [35]. IFN- $\gamma$ was known to induce intestinal vessels' permeability by disrupting the vascular endothelial cadherin junction which associated with tissue injury and progression of Crohn's disease [36]. Therefore, our result signifies that TPEE treatment could reduce inflammatory responses in the gastrointestinal tract and improve gut health in OVX rats through the possible reduction of TLR4, RELA and c-maf in the IBD associated pathways.

PPARs belong to the nuclear hormone receptors that are activated by fatty acids and their derivatives. PPARs play a critical role in modulating the gene expressions which involves in the glucose and lipid metabolism, adipogenesis and inflammation [37, 38]. PPAR signaling pathway was predicted to be lower in the TPEE treated group than in the NC group. The significant KOs discovered in this pathway were composed of SCD-1 and GyK genes, which associated with lipogenesis and gluconeogenesis, respectively. These KOs were modulated by one of the PPAR subtypes, PPAR $\gamma$, which involves in lipid metabolism. Another significant KOs determined in this pathway were ILK and APOA1 genes, they are modulated by PPAR $\beta / \delta$ and PPAR $\alpha$, respectively. PPAR $\beta / \delta$ involves in lipid oxidation and adipocyte differentiation [39] while PPAR $\alpha$ regulates lipid metabolism and homeostasis [37]. Our result from this prediction analysis suggests that the reduced level of TG in the TPEE treated group could be associated with the reduced abundance of sequence reads related to SCD-1 in the lipogensis pathway. 
At the phylum level, the correlation between Bacteriodetes and the levels of serum HDL, TG, and TCHOL denoted that the abundance of Bacteriodetes in the gut was highly desirable in maintaining healthy blood cholesterol. Contrarily, Proteobacteria phyla have shown unfavorable influence on the serum lipid profile. Clustering analysis based on Ward variance minimization algorithm shows the distinctness of Proteobacteria phylum according to its relationship with the serum lipid biomarkers and liver enzymes. We also found that the correlation between B. pseudolongum group and the serum biomarkers provides promising evidence that $B$. pseudolongum group might possess hepaprotective and hypocholesterolemic properties. Previous study has reported B. pseudolongum treatment was able to reduce serum TG level and has potential therapeutic implication for the treatment of diet-induced obesity [40].

A healthy gastrointestinal tract can be characterized by the predominant residency of obligate anaerobes like Firmicutes and Bacteroidetes [41]. Major studies have upheld that low $\mathrm{F} / \mathrm{B}$ ratio denotes healthy gut condition [42] while increased $F / B$ ratio is associated with obesity [43]. A significantly low F/B ratio was observed in Sham group whereas a significantly high F/B ratio was observed in the $\mathrm{NC}$ group. Estradiol and TPEE interventions were seen to reduce the F/B ratio in the OVX rats, denoting a reduction in microbial dysbiosis in the OVX rats. Previous study reported that Lactobacillus rhamnosus hsryfm 1301, from the phylum Firmicutes, reduced serum lipid levels in the rats [44]. In our serum biomarker analysis, TPEE treatment significantly reduced serum TG levels compared to those in the NC group (Fig. 2).

A. muciniphila belongs to the phylum Verrucomicrobia which showed negative correlation with serum TCHOL and LDL/VLDL levels but positive correlation with serum HDL level in Spearman analysis (Fig. 4B). In previous studies, the role of $A$. muciniphila in obesity [45] and diabetes [46] has been reported. A. muciniphila was known as a promising probiotic which promote the intestinal health and showing negative correlation with the occurrence of diabetes [43]. On top of that, a collective of studies have reported that $A$. muciniphila plays a crucial role in keeping the intestinal barrier intact, maintaining the permeability of intestinal mucosa and preventing the occurrence of inflammatory response in the host [43]. Therefore, TPEE could serve as a therapeutic option for boosting the growth of $A$. muciniphila to manage inflammatory diseases.

Probiotics are known for their function in the transformation of phytoestrogens, which include daidzein, genistein, formononetin, and biochanin A. The metabolites of these compounds commonly exhibit higher bioavailability, as well as higher estrogenic, antiestrogenic, and antioxidant bioactivities, than their precursors [47]. Formononetin can be converted to daidzein, and sequentially metabolized into equol by intestinal floral; from a pharmacodynamic perspective, this reaction pathway is noteworthy because equol has significantly higher estrogenic potency than its precursor [48]. Kawada et al. Y Kawada, S Yokoyama, E Yanase, T Niwa and T Suzuki [49] previously identified Lactococcus sp. strain 20-92, Slackia sp. strain NATTS, and Slackia isoflavoniconvertens as the bacterial strains found in the human intestine that convert daidzein into equol. Previous study investigated the effects of fermented red clover extract in the presence of a heterogeneous culture of probiotic lactic acid bacteria. Their results showed that $55 \%$ of the patients became equol producers after treated with fermented red clover extract for 6 months [18]. These studies suggested that the probiotics in their sample induced the intestinal bacterial milieu of the patients, thereby producing a bacterial composition favorable to equol production. Therefore, TPEE treatment in our study may have introduced a certain amount of gastrointestinal phytoestrogen that in turn potentially increased the abundance of Lactococcus sp. in the gut microbiota and potentiated equol production. Besides, Lactococcus sp. could be a target for further study because of its ability to convert biochanin $\mathrm{A}$ and formononetin into equol and thereby enhance estrogenic activity.

Identifying the composition of TPEE using GC-MS analysis led us to the discovery of 18 functional phytocomponents that could contribute to its bioactivities. To our best knowledge, no previous study has reported the presence of mome inositol in T. pratense. Mome inositol possesses cholesterolytic and lipotropic activities [50]. The hypocholesterolemic effect of TPEE reported in this study might be attributed to the presence of mome inositol. It was identified as the major constituent in the methanolic extract of Corbichonia decumbens (Forssk.) Exell (Molluginaceae) root and stem which was reported to possess anti-inflammatory effects which made it beneficial as an antiulcer drug [51]. Interestingly, the less abundant compounds, ethane, 1,1-diethoxy- and hexadecanoic acid, found in TPEE were reported in previous studies to possess properties which could improve complications related to cardiovascular diseases.

Hexadecanoic acid, another phytocomponent found in TPEE, was previously reported to exhibit hypocholesterolemic effects $[52,53]$. From the serum biomarker analysis in this study, TPEE exhibited regulatory effects on the serum lipid biomarkers levels compared to NC group. Ethane, 1,1-diethoxy-, identified in TPEE by GC-MS analysis in this study, have shown to have therapeutic properties such as anti-inflammatory, antipyretic, and antithrombotic effect [54]. The presence of these 
compounds harmonized with our findings on TPEE's effect on the serum biomarkers that correspond to cardiovascular diseases. The hypocholesterolemic effects of TPEE may be also attributed to the presence of phytoestrogen which could alter the hepatic metabolism with increased LDL and VLDL removal by hepatocytes $[55,56]$. We found that the levels of liver enzymes and biomarkers (AST, ALT, ALP, ALB, and TBIL) were not affected by OVX-induced menopausal condition in rats. The discovery of the major phytocomponent, mome inositol, in TPEE also warrants future research on the mechanism of action of this compound which linked to the regulation of metabolism pathways and gut microbiota composition.

The current study has revealed the potential associations between TPEE treatment and the changes in the gut microbiota composition as well as the changes of lipid profiles in the OVX rats. For future studies, the causation analysis would require fecal bacteria transplantation or potential single strain probiotic identified in this study (B. pseudolongum group, A. muciniphila and Lactococcus sp.) into germ-free host or OVX model. Further investigation on the lipid profile changes and the mechanism of actions in the germ-free or the experimental menopausal host is warranted in the future.

\section{Conclusions}

The current study reported for the first time that mome inositol was identified as the major phytocomponent in TPEE by GC-MS analysis. TPEE intervention potentially ameliorated the gut health and regulate serum lipid levels by yielding lower abundance of sequence reads associated with IBD and PPAR pathways. TPEE treatment also improved intestinal microbiota composition of OVX rats with predominant residency of Firmicutes and Bacteroidetes. Collectively, our analyses indicate that TPEE possesses hypocholesterolemic effects and shows potential for reducing risk factors for coronary heart diseases. TPEE showed complementary effects with PomE on the regulation of serum ALP, ALT, AST, TG, HDL, and LDL/VLDL levels. Therefore, our study suggests that co-administration of TPEE and PomE could be considered as a potential substitute for E treatment to achieve the similar therapeutic effects on the recovery of serum biomarkers.

\footnotetext{
Abbreviations

ALB: Serum albumin; ALP: Serum alkaline phosphatase; ALT: Serum alanine aminotransferase; APOA1: Apolipoprotein A-I; AST: Serum aspartate aminotransferase; c-maf: Transcription factor Maf; E: Estradiol; ELISA: Enzyme-linked immunosorbent assay; GC-MS: Gas chromatography mass spectrometry; GyK: Glycerol kinase; HDL: High-density lipoprotein; HPLC: High performance liquid chromatography; IBD: Inflammatory bowel disease; ILK:
}

Integrin-linked kinase; KO: KEGG orthology; LC-MS/MS: Liquid chromatography with tandem mass spectrometry; LDL/VLDL: Low-density lipoprotein/very low-density lipoprotein; NC: Negative control; OTUs: Operational taxonomic unit; OVX: Ovariectomized; PCoA: Principal coordinate analysis; PC1: Principal coordinate 1; PomE: Pomegranate extract; PPAR: Peroxisome proliferator-activated receptor; RELA: Transcription factor p65; RXR: Retinoid-X receptor beta; SCD-1: Stearoyl-coA desaturase; TBIL: Serum total bilirubin; TCHOL: Serum total cholesterol; TG: Serum triglyceride; TLR4: Toll-like receptor 4; TPEE: Trifolium pratense ethanolic extract.

\section{Supplementary Information}

The online version contains supplementary material available at https://doi. org/10.1186/s12906-021-03486-w.

Additional file 1. Species identification of T. pratense. The DNA sequencing data obtained was $100 \%$ identical to previously reported sequences of T. pratense in the genetic sequence database. The dried Trifolium pratense was shown on the right.

Additional file 2. A diagram illustrating the preparation of T. pratense ethanolic extract (TPEE) and the yield of functional indicator components (formononetin and biochanin A).

Additional file 3. Timeline of the experiments. A total of seven groups of rats were used in this study, each group consists of 10 animals $(n=10)$. After 1 week of acclimatization, 6 groups of rats were subjected to ovartiectomization and one group was subjected to Sham operation. The operated rats were given one more week for recovery before the commencement of oral administration.

Additional file 4. The number of reads and the read lengths for each sample.

Additional file 5. Representative images of H\&E-stained rat liver were shown. All images were acquired under $\times 400$ magnification. Scale bar: $100 \mu \mathrm{m}$.

Additional file 6. Alpha diversity indices including rarefaction curves for all the treatment groups.

\section{Acknowledgements}

Not applicable.

\section{Authors' contributions}

Y.Q., S-J.L., and S-C.P. conceptualized, designed the experiments, and revised the manuscript; Y.Q., N-H.P., E-B.L., K-J.L., M.S.A., S-H.J., and M-J.K. performed the experiments, interpreted, analyzed, and validated the data. For animal experiment, four different investigators were involved as follows: the first investigator (Y.Q.) carried out the oral administration whom was the only person aware of the allocation of the treatment group. The other three investigators (N-H.P., E-B.L., and M.S.A.), unaware of treatments, performed the anaesthetic procedure and collection of specimens. J.C.Y-L. performed the software analysis; Y.Q. prepared the original draft of the manuscript; S-C.P. and S-J.L. supervised the execution of the experiment. All authors have read and agreed to the published version of the manuscript.

\section{Authors' information}

Seung-Chun Park and Seung-Jin Lee contributed equally to the supervision of the study.

\section{Funding}

This research was financially supported by the Ministry of Small and Mediumsized Enterprises and Startups (MSS), Korea, under the "Regional Specialized Industry Development Program (R\&D, P0002954)" supervised by the Korea Institute for Advancement of Technology (KIAT) and in part in part by a grant (Z-1543081-2020-22-02) from the Animal and Plant Quarantine Agency, Ministry of Agriculture, Food and Rural Affairs, Republic of Korea. The manuscript is based on part of the first author's doctoral dissertation conducted at Kyungpook National University. 


\section{Availability of data and materials}

All raw sequence reads obtained in this study are available in the NCBI SRA database under project accesion number PRJNA763709. The plant sample datasets generated and/or analysed during the current study are available in the Sequence Read Archive (SRA) repository, accession number: SRR14492033, under the project number PRJNA727441.

\section{Declarations}

\section{Ethics approval and consent to participate}

This animal study was approved by the Ethics Committee of Kyungpook National University (approval number: KNU 2018-121, date of approval: 1st August 2018). Animal handling complied with ARRIVE guidelines and was performed in compliance with the Guide for the Care and Use of Laboratory Animals provided by the US National Institutes of Health.

\section{Consent for publication}

Not applicable.

\section{Competing interests}

The authors declare no conflict of interest.

\begin{abstract}
Author details
${ }^{1}$ College of Veterinary Medicine, Kyungpook National University, 80 Daehak-ro, Daegu 41566, Republic of Korea. ${ }^{2}$ Laboratory Animal Center, Daegu-Gyeongbuk Medical Innovation Foundation, Daegu, Republic of Korea. ${ }^{3}$ Department of Finance, Faculty of Business and Finance, Universiti Tunku Abdul Rahman, Jalan Universiti, Bandar Barat, 31900 Kampar, Perak, Malaysia. ${ }^{4}$ Centre of loT and Big Data, Universiti Tunku Abdul Rahman, 31900 Kampar, Perak, Malaysia. ${ }^{5}$ Department of Biomedical Science and Department of Pharmacology, School of Medicine, Brain Science and Engineering Institute, Kyungpook National University, Daegu, Republic of Korea. ${ }^{6}$ Department of Pharmacy, International Islamic University Chittagong, Kumira, Chittagong 4318, Bangladesh. ${ }^{7}$ Teazen Co. Ltd., Gyegok-myeon, Haenam-gun, Jeollanam-do 59017, Republic of Korea. ${ }^{8}$ Reproductive and Development Toxicology Research Group, Korea Institute of Toxicology, Daejeon, Republic of Korea.
\end{abstract}

Received: 27 April 2021 Accepted: 9 December 2021 Published online: 04 January 2022

\section{References}

1. Lems WF, Raterman HG. Critical issues and current challenges in osteoporosis and fracture prevention. An overview of unmet needs. Ther Adv Musculoskelet Dis. 2017;9:299-316. https://doi.org/10.1177/1759720X17 732562.

2. Tankó LB, Christiansen C, Cox DA, Geiger MJ, McNabb MA, Cummings SR. Relationship between osteoporosis and cardiovascular disease in postmenopausal women. J Bone Miner Res. 2005;20:1912-20. https://doi. org/10.1359/JBMR.050711.

3. Mason AS. The events of the menopause. R Soc Health J. 1976;96(2):70-1. https://doi.org/10.1177/146642407609600208.

4. Ko S-H, Kim H-S. Menopause-associated lipid metabolic disorders and foods beneficial for postmenopausal women. Nutrients. 2020;12:202. https://doi.org/10.3390/nu12010202.

5. Luís Â, Domingues F, Pereira L. Effects of red clover on perimenopausal and postmenopausal women's blood lipid profile: a meta-analysis. Climacteric. 2018;21:446-53. https://doi.org/10.1016/j.maturitas.2019.11. 001.

6. Kolodziejczyk-Czepas J. Trifolium species-derived substances and extracts - biological activity and prospects for medicinal applications. J Ethnopharmacol. 2012;143(1):14-23. https://doi.org/10.1016/j.jep.2012. 06.048 .

7. Sansanelli S, Tassoni A. Wild food plants traditionally consumed in the area of Bologna (Emilia Romagna region, Italy). J Ethnobiol Ethnomed. 2014;10:69. https://doi.org/10.1186/1746-4269-10-69.

8. Polat R, Çakılcıoğlu U, Ulusan MD, Paksoy MY. Survey of wild food plants for human consumption in Elazığ (Turkey). Indian J Tradit Knowl. 2014;1:69-75.
9. Malca-Garcia GR, Zagal D, Graham J, Nikolić D, Friesen JB, Lankin DC, et al. Dynamics of the isoflavone metabolome of traditional preparations of Trifolium pratense L. J Ethnopharmacol. 2019;238:111865. https://doi.org/ 10.1016/j.jep.2019.111865.

10. Sabudak T, Guler N, Trifolium L. A review on its phytochemical and pharmacological profile. Phytother Res. 2009;23:439-46.

11. Khan SW, Khatoon S. Ethnobotanical studies on some useful herbs of Haramosh and Bugrote valleys in Gilgit, northern areas of Pakistan. Pak J Bot. 2008:40(1):3-58.

12. Mustafa B, Hajdari A, Krasniqi F, Hoxha E, Ademi H, Quave CL, et al. Medical ethnobotany of the Albanian Alps in Kosovo. J Ethnobiol Ethnomed. 2012;8(1):6. https://doi.org/10.1186/1746-4269-8-6.

13. Sõukand R, Kalle R. Where does the border lie: locally grown plants used for making tea for recreation and/or healing, 1970s-1990s Estonia. J Ethnopharmacol. 2013;150:162-74. https://doi.org/10.1016/j.jep.2013.08. 031.

14. Chen LR, Ko NY, Chen KH. Isoflavone supplements for menopausal women: a systematic review. Nutrients. 2019;11. https://doi.org/10.3390/ nu11112649.

15. Kawakita S, Marotta F, Naito Y, Gumaste U, Jain S, Tsuchiya J, et al. Effect of an isoflavones-containing red clover preparation and alkaline supplementation on bone metabolism in ovariectomized rats. Clin Interv Aging. 2009:4:91-100. https://doi.org/10.2147/cia.s4164.

16. Vishali N, Kamakshi K, Suresh S, Prakash S. Red clover Trifolium pratense (Linn.) isoflavones extract on the pain threshold of normal and ovariectomized rats -a long-term study. Phytother Res. 2011;25:53-8. https://doi. org/10.1002/ptr.3217.

17. Zhao H, Chen J, Li X, Sun Q, Qin P, Wang Q. Compositional and functional features of the female premenopausal and postmenopausal gut microbiota. FEBS Lett. 2019;593:2655-64. https://doi.org/10.1002/1873-3468. 13527.

18. Lambert MNT, Thybo CB, Lykkeboe S, Rasmussen LM, Frette X, Christensen LP, et al. Combined bioavailable isoflavones and probiotics improve bone status and estrogen metabolism in postmenopausal osteopenic women: a randomized controlled trial. Am J Clin Nutr. 2017;106:909-20. https://doi.org/10.3945/ajcn.117.153353.

19. Wang SWJ, Chen Y, Joseph T, Hu M. Variable isoflavone content of red clover products affects intestinal disposition of biochanin a, formononetin, genistein, and daidzein. Journal of alternative and complementary medicine. J Altern Complement Med. 2008;14(3):287-97. https://doi.org/ 10.1089/acm.2007.0617.

20. Setchell KDR, Clerici C, Lephart ED, Cole SJ, Heenan C, Castellani D, et al. S-Equol, a potent ligand for estrogen receptor $\beta$, is the exclusive enantiomeric form of the soy isoflavone metabolite produced by human intestinal bacterial flora. Am J Clin Nutr. 2005;81:1072-9. https://doi.org/ 10.1093/ajcn/81.5.1072.

21. Beck V, Rohr U, Jungbauer A. Phytoestrogens derived from red clover: an alternative to estrogen replacement therapy? J Steroid Biochem Mol Biol. 2005;94:499-518. https://doi.org/10.1016/j.jsbmb.2004.12.038.

22. Zhuo M, Jinghui L, Zhang W. Hormonal regulation of cholesterol homeostasis. In: Nagpal ML, editor. Cholesterol - good, bad and the heart. London: IntechOpen; 2018. https://doi.org/10.5772/intechopen.76375.

23. An X, Bao Q, Di S, Zhao Y, Zhao S, Zhang H, et al. The interaction between the gut microbiota and herbal medicines. Biomed Pharmacother. 2019;118:109252. https://doi.org/10.1016/j.biopha.2019.109252.

24. Quah Y, Lee E-B, Chan JY-L, Jang S-H, Park S-C. Optimal red clover ethanolic extract by relative aggregated metric increases osteoblastic activity and nuclear factor kappa-B ligand gene expression in SaOS-2 cells. All Life. 2020;13:321-7. https://doi.org/10.1080/26895293.2020.1771435.

25. Rossouw JE, Anderson GL, Prentice RL, LaCroix AZ, Kooperberg C, Stefanick $M L$, et al. Risks and benefits of estrogen plus progestin in healthy postmenopausal women: principal results from the women's health initiative randomized controlled trial. JAMA. 2002;288:321-33. https://doi. org/10.1001/jama.288.3.321.

26. Ahmad NS, Isa NM. Pomegranate use to attenuate bone loss in major musculoskeletal diseases: An evidence-based review. Curr Drug Targets. 2013;14:1565-78. https://doi.org/10.2174/1389450114666131108155039.

27. Spilmont M, Léotoing L, Davicco M-J, Lebecque P, Mercier S, Miot-Noirault E, et al. Pomegranate and its derivatives can improve bone health through decreased inflammation and oxidative stress in an animal model 
of postmenopausal osteoporosis. Eur J Nutr. 2014;53:1155-64. https://doi. org/10.1007/s00394-013-0615-6.

28. Kum E-J, Kwon D-H, Shin H-S. Analysis of estrogen in pomegranate extract by solid phase extraction and liquid chromatography tandem mass spectrometry. J Food Hyg Saf. 2010;25:79-82.

29. Yoon S-H, Ha S-M, Kwon S, Lim J, Kim Y, Seo H, et al. Introducing EzBioCloud: a taxonomically united database of 16S rRNA gene sequences and whole-genome assemblies. Int J Syst Evol. 2017;67:1613-7. https://doi. org/10.1099/ijsem.0.001755.

30. Langille MGI, Zaneveld J, Caporaso JG, McDonald D, Knights D, Reyes JA et al. Predictive functional profiling of microbial communities using $16 \mathrm{~S}$ rRNA marker gene sequences. Nat Biotechnol. 2013;31:814-21. https:// doi.org/10.1038/nbt.2676.

31. Kanehisa M, Goto S. KEGG: Kyoto encyclopedia of genes and genomes. Nucleic Acids Res. 2000;28:27-30. https://doi.org/10.1093/nar/28.1.27.

32. Kanadys W, Baranska A, Jedrych M, Religioni U, Janiszewska M. Effects of red clover (Trifolium pratense) isoflavones on the lipid profile of perimenopausal and postmenopausal women- a systematic review and meta-analysis. Maturitas. 2020;132:7-16. https://doi.org/10.1016/j.matur itas.2019.11.001.

33. Ahluwalia B, Moraes L, Magnusson MK, Öhman L. Immunopathogenesis of inflammatory bowel disease and mechanisms of biological therapies. Scand J Gastroenterol. 2018;53:379-89. https://doi.org/10.1080/00365 521.2018.1447597.

34. Liu L, Zhou L, Yang X, Liu Q, Yang L, Zheng C, et al. 17beta-estradiol attenuates ovariectomyinduced bone deterioration through the suppression of the ephA2/ephrinA2 signaling pathway. Mol Med Rep. 2018;17:1609-16. https://doi.org/10.3892/mmr.2017.8042.

35. Han X, Ding S, Jiang H, Liu G. Roles of macrophages in the development and treatment of gut inflammation. Front Cell Dev Biol. 2021;9:385. https://doi.org/10.3389/fcell.2021.625423.

36. Langer V, Vivi E, Regensburger D, Winkler TH, Waldner MJ, Rath T, et al. IFN- $\gamma$ drives inflammatory bowel disease pathogenesis through VE-cadherin-directed vascular barrier disruption. J Clin Invest. 2019;129:4691707. https://doi.org/10.1172/JCl124884.

37. Tan Y, Wang M, Yang K, Chi T, Liao Z, Wei P. PPAR-a modulators as current and potential cancer treatments. Front Oncol. 2021;11:707. https://doi. org/10.3389/fonc.2021.599995.

38. Botta M, Audano M, Sahebkar A, Sirtori CR, Mitro N, Ruscica M. PPAR agonists and metabolic syndrome: an established role? Int J Mol Sci. 2018;19:1197. https://doi.org/10.3390/ijms19041197.

39. Matsusue K, Peters JM, Gonzalez FJ. PPARß/ $\delta$ potentiates PPARYstimulated adipocyte differentiation. FASEB J. 2004;18:1477-9. https://doi. org/10.1096/fj.04-1944fje.

40. Bo T-B, Wen J, Zhao Y-C, Tian S-J, Zhang X-Y, Wang D-H. Bifidobacterium pseudolongum reduces triglycerides by modulating gut microbiota in mice fed high-fat food. J Steroid Biochem Mol Biol. 2020;198:105602. https://doi.org/10.1016/j.jsbmb.2020.105602.

41. Xu J, Zhao Y, Aisa HA. Anti-inflammatory effect of pomegranate flower in lipopolysaccharide (LPS)-stimulated RAW264.7 macrophages. Pharm Biol. 2017;55:2095-101. https://doi.org/10.1080/13880209.2017.1357737.

42. Song C-H, Kim N, Nam RH, Choi SI, Lee H-N, Surh Y-J. 17ß-estradiol supplementation changes gut microbiota diversity in intact and colorectal cancer-induced ICR male mice. Sci Rep. 2020;10:1-14. https://doi.org/10. 1038/s41598-020-69112-w.

43. Bu F, Zhang S, Duan Z, Ding Y, Chen T, Wang R, et al. A critical review on the relationship of herbal medicine, Akkermansia muciniphila, and human health. Biomed Pharmacother. 2020;128:110352. https://doi.org/10. 1016/j.biopha.2020.110352.

44. Chen D, Yang Z, Chen X, Huang Y, Yin B, Guo F, et al. The effect of lactobacillus rhamnosus hsryfm 1301 on the intestinal microbiota of a hyperlipidemic rat model. BMC Complement Altern Med. 2014;14:386. https://doi. org/10.1186/1472-6882-14-386.

45. Schneeberger M, Everard A, Gómez-Valadés AG, Matamoros S, Ramírez S, Delzenne NM, et al. Akkermansia muciniphila inversely correlates with the onset of inflammation, altered adipose tissue metabolism and metabolic disorders during obesity in mice. Sci Rep. 2015;5:16643. https://doi.org/ 10.1038/srep 16643

46. Zhang L, Qin Q, Liu M, Zhang X, He F, Wang G. Akkermansia muciniphila can reduce the damage of gluco/lipotoxicity, oxidative stress and inflammation, and normalize intestine microbiota in streptozotocin-induced diabetic rats. Pathog Dis. 2018;76(4). https://doi.org/10.1093/femspd/ fty028.

47. Gaya P, Medina M, Sánchez-Jiménez A, Landete JM. Phytoestrogen metabolism by adult human gut microbiota. Molecules. 2016;21:1034. https://doi.org/10.3390/molecules21081034.

48. Mayo B, Vázquez L, Flórez AB. Equol: a bacterial metabolite from the daidzein isoflavone and its presumed beneficial health effects. Nutrients. 2019;11:2231. https://doi.org/10.3390/nu11092231.

49. Kawada Y, Yokoyama S, Yanase E, Niwa T, Suzuki T. The production of S-equol from daidzein is associated with a cluster of three genes in Eggerthella sp. YY7918. Biosci Microbiota Food Health. 2016;35:113-21. https://doi.org/10.12938/bmfh.2015-023.

50. Das S, Vasudeva N, Sharma S. Chemical composition of ethanol extract of Macrotyloma uniflorum (lam.) Verdc. Using GC-MS spectroscopy. Org Med Chem Lett. 2014;4:1-4. https://doi.org/10.1186/s13588-014-0013-y.

51. Arora S, Saini M. Gas chromatography mass spectrometry profiling in methanolic and ethyl-acetate root and stem extract of Corbichonia decumbens (Forssk.) Exell from Thar Desert of Rajasthan, India. Pharm Res. 2017;9:S48-52. https://doi.org/10.4103/pr.pr_62_17.

52. Jancy Rani P, Maria P, Kannan SM, Kumaravel S. Screening of antioxidant activity, total phenolics and gas chromatograph and mass spectrometer (GC-MS) study of delonix regia. Afr J Biochem Res. 2011;2:341-7. https:// doi.org/10.5897/AJBR.9000211.

53. Jain $R$, Singh $M$, Dezman DJ. Qualitative and quantitative characterization of phenolic compounds from Lantana (Lantana camara) leaves. Weed Sci. 1989;37:302-7. https://doi.org/10.1017/S0043174500071964.

54. Al-Wathnani H, Ara I, Tahmaz R, Al-Dayel T, Bakir M. Bioactivity of natural compounds isolated from cyanobacteria and green algae against human pathogenic bacteria and yeast. J Med Plant Res. 2012;6:3425-33. https:// doi.org/10.5897/JMPR1 1.1746.

55. Owen AJ, Roach PD, Abbey M. Regulation of low-density lipoprotein receptor activity by estrogens and phytoestrogens in a HepG2 cell model. Ann Nutr Metab. 2004;48:269-75. https://doi.org/10.1159/00008 0462.

56. Wroblewski Lissin L, Cooke JP. Phytoestrogens and cardiovascular health. J Am Coll Cardiol. 2000;35:1403-10. https://doi.org/10.1016/s07351097(00)00590-8.

\section{Publisher's Note}

Springer Nature remains neutral with regard to jurisdictional claims in published maps and institutional affiliations.

Ready to submit your research? Choose BMC and benefit from:

- fast, convenient online submission

- thorough peer review by experienced researchers in your field

- rapid publication on acceptance

- support for research data, including large and complex data types

- gold Open Access which fosters wider collaboration and increased citations

- maximum visibility for your research: over $100 \mathrm{M}$ website views per year

At BMC, research is always in progress.

Learn more biomedcentral.com/submissions 